\title{
Transurethral incision of duplex system ureteroceles in neonates: does it increase the need for secondary surgery in intravesical and ectopic cases?
}

\author{
M. CASTAGNETTI, M. CIMADOR, M. SERGIO and E. de GRAZIA \\ E. Albanese Hospital, Paediatric Surgery Unit, University of Palermo, Palermo, Italy \\ Accepted for publication 10 February 2004
}

\section{OBJECTIVE}

To evaluate the relevance of ureterocele ectopia and associated reflux on the outcome of duplex system ureteroceles (DSU) after neonatal transurethral incision (TUI).

\section{PATIENTS AND METHODS}

The study included 41 neonates with a diagnosis of DSU; the ureterocele was ectopic in 24 (58\%). Before TUI, vesico-ureteric reflux (VUR) was present in 13 lower moieties (32\%) and seven contralateral ureters (17\%). TUI was always performed within the first month of life. The follow-up and management were tailored for each patient from the findings at ultrasonography, voiding cystourethrography and renal scintigraphy. Results of intravesical and ectopic
DSU were compared using Fisher's exact test.

\section{RESULTS}

TUI was effective in allowing ureteric decompression in all but one patient (2.4\%). After TUI, VUR ceased in six lower ipsilateral moieties and in two contralateral ureters, while new VUR occurred in three contralateral kidneys. De novo VUR in the punctured moiety appeared in 13 cases (32\%). Nine upper poles were not functioning. Twentyone patients $(51 \%)$ required secondary surgery. Ureteric reimplantation was indicated exclusively for reflux in the punctured moiety in only in two cases (5\%), while in a further two iatrogenic reflux in a nonfunctioning upper moiety required total heminephroureterectomy. There was no significant difference between intravesical and ectopic ureteroceles in the occurrence of VUR in the punctured moiety, rate of nonfunctioning upper poles or need for secondary surgery.

\section{CONCLUSIONS}

About half of the patients with a DSU need secondary surgery, but this is rarely indicated for de novo reflux in the punctured moiety only. The need for secondary surgery was greater whenever there was associated reflux before endoscopic incision. There was no difference in the outcome of intravesical and ectopic ureteroceles and such distinction seems no longer to be of clinical relevance.

\section{KEYWORDS}

neonates, duplex system ureterocele, endoscopic incision, secondary surgery

\section{INTRODUCTION}

Managing urinary tract malformations in neonates involves the problems of working on small and still immature anatomical structures. In this setting assessing renal function is not easy, spontaneous improvement can be expected and surgery is often challenging. This has prompted a conservative approach to many of these malformations. However, in case of obstructive uropathy, postponing surgery could cause an impairment of postnatal renal maturation and thus permanent loss of renal function that is otherwise salvageable [1]. For this reason transurethral incision (TUI) of ureteroceles, being a minimally invasive way to resolve impaired urinary flow, has become very popular as the initial treatment of ureteroceles in children and neonates [2,3]. Indeed, there is general agreement about its effectiveness in treating single-system or intravesical ureteroceles, and whenever there is urosepsis or BOO [3-7]. However, controversies remain about its effectiveness in duplex-system ureteroceles (DSU) and especially when the ureterocele is ectopic [6-8]. Recent series reported that in this case patients initially treated with an endoscopic approach often required additional surgical procedures because of persistent VUR either in the lower pole or contralateral kidneys, de novo VUR in the punctured ureterocele moiety and/or a nonfunctioning upper pole [6,7,9-12]. Moreover, opponents of TUI maintain that in a DSU the upper moiety function is often negligible and the potential for recovery poor, the parenchyma being almost always dysplastic [13-16]. Thus the risk of secondary surgery would often overcome the advantage of retaining the upper pole, and thus primary total reconstruction [17] or upper pole nephrectomy [18] have been advised.
The aim of the present study was to analyse the role of endoscopic TUI as the initial management of DSU in neonates and to discuss if factors such as ureterocele position (intravesical or ectopic) or the presence of VUR before incision, affect the outcome and need for secondary surgery; the ideal surgical management based on present knowledge is discussed.

\section{PATIENTS AND METHODS}

The study included 41 neonates (29 female and 12 male) with a diagnosis of DSU referred to our institution between 1991 and 2001. The ureterocele was diagnosed by prenatal ultrasonography (US) in 31 (76\%), during neonatal screening in eight (20\%) and after a UTI in the remaining two (4\%). The ureterocele was on the left in 23 cases (56\%) and on the right in 18 (44\%); none was 
bilateral. Twenty-four (59\%) were ectopic, according to the definition of the Terminology Committee of the American Academy of Pediatrics [19] (five protruding into the urethra, the others at the bladder neck). Definitive assignment to the intravesical or ectopic group was possible only after cystoscopy in 10 cases (25\%). Before incision, voiding cysto-urethrography (VCUG) showed VUR in 20 (49\%) cases, 13 (32\%) in the lower moiety and seven (17\%) in the contralateral ureter. None of the ureterocele moieties had VUR before TUI, while all of them had some degree of pelvic and/or calyceal dilatation associated with a parenchymal thinning on US; the latter also allowed visualization of the retrovesical ureter in 14 cases (35\%).

The evaluation before TUI included only US and VCUG; low-dose antibiotic prophylaxis was administered to all children and was maintained until VCUG showed no reflux. TUI was performed during the first month of life in all cases (mean 2.7 weeks), through an $8 \mathrm{~F}$ cystoscope using a straightened loop of the resector. TUI consisted of a low transverse opening $(\approx 2 \mathrm{~mm})$ of the intravesical portion of the ureterocele at the level of the junction between the ureterocele and the bladder wall. Good drainage of the ureter was checked during TUI, watching urine coming from the incision site during an external compression on the homolateral flank, and after TUI by US. The same incision was created in intravesical and ectopic ureteroceles. No incision was made in the ureterocele portion encroaching the bladder neck or urethra.

The follow-up comprised US, VCUG and renal nuclear scintigraphy using MAG-3 and/or DMSA at 6 and 12 months after TUI.

Thereafter, the policy was to tailor the management and subsequent follow-up to the features of each case. Those babies with good renal function and no VUR were considered cured, and followed with US every 6 months; VCUG was repeated only if clinically indicated. Low-grade reflux in contralateral ureters was managed with an endoscopic injection of a bulking agent. Ureteric reimplantation with ureterocele excision was used whenever VUR persisted in the ureterocele-bearing moiety at 6 months and 1 year on VCUG, whether the upper pole was visualized at scintigraphy, or if reflux persisted in any other moiety after endoscopic treatment. An upper pole partial nephrectomy was used whenever the 1-year renal scan showed no functioning in the

\begin{tabular}{|c|c|c|c|}
\hline VUR & Intravesical & Ectopic & \multirow{22}{*}{$\begin{array}{l}\text { TABLE } 1 \\
\text { Reflux before and after TUI }\end{array}$} \\
\hline \multicolumn{3}{|l|}{ Before TUI: } & \\
\hline Ureterocele moiety & 0 & 0 & \\
\hline Lower pole ureter & 4 & 9 & \\
\hline Contralateral ureter & 3 & 4 & \\
\hline \multicolumn{3}{|l|}{ After TUI } & \\
\hline Ureterocele moiety & 6 & 7 & \\
\hline \multicolumn{3}{|l|}{ Lower pole ureter } & \\
\hline ceased & 2 & 4 & \\
\hline unchanged & 3 & 4 & \\
\hline new & 0 & 0 & \\
\hline \multicolumn{3}{|l|}{ Contralateral ureter } & \\
\hline ceased & 1 & 1 & \\
\hline unchanged & 2 & 3 & \\
\hline new & 2 & 1 & \\
\hline \multicolumn{3}{|l|}{ Secondary surgery after TUI } & \\
\hline Endoscopic injection & 2 & 1 & \\
\hline Ureteric reimplantation & 3 & 6 & \\
\hline Upper pole partial nephrectomy & 2 & 5 & \\
\hline Total reconstruction & 1 & 1 & \\
\hline Total & $8 / 17$ & $13 / 24$ & \\
\hline \multicolumn{3}{|c|}{$\begin{array}{l}\text { There was no statistical difference in the secondary operation rate } \\
\text { between intravesical and ectopic ureteroceles, considering each } \\
\text { procedure or overall. }\end{array}$} & \\
\hline
\end{tabular}

upper pole. Patients with VUR in several moieties and poorly functioning upper poles were selected for total reconstruction.

Fisher's exact test was used to compare the results between intravesical and ectopic ureteroceles, with significance indicated at $P<0.05$.

\section{RESULTS}

There were no intraoperative complications; US after TUI showed an effective urinary tract decompression (disappearance or significant improvement of uretero-hydronephrosis from before TUI) in all patients but one. In the latter a second puncture was successful. There was a mean increase in thickness of the renal parenchyma at the 1-year follow-up, from 3.4 to $6.3 \mathrm{~mm}$.

After TUI there were various combinations of resolution and appearance of VUR in moieties with no ureterocele; the distribution of VUR before and after TUI is shown in Table 1.

Reflux ceased in eight ureters (six ipsilateral lower pole and two contralateral) while there was new VUR in three contralateral ureters. There was iatrogenic VUR in the ureterocele moieties in 13 patients (31\%) after TUI; seven were ectopic and six intravesical $(P>0.05)$. Ten patients eventually had bladder surgery and three resolved spontaneously.

Renal scintigraphy at 0.5 and 1 year showed no upper pole function in nine of the 41 patients (22\%) and therefore the upper pole was removed. A nonfunctioning upper pole was more common in ectopic ureteroceles, but the difference between ectopic and intravesical was not significant $(P>0.05)$. No pyelonephritis was recorded during the follow-up. After 6-12 months TUI cured 20 children (49\%) while the remaining 21 (51\%) required further surgery (Fig. 1). Three (7\%) had endoscopic treatment of VUR in the contralateral ureter and 17 (42\%) an opening procedure. There was reflux only in the ureterocele-bearing ureter in four (10\%), two having a functioning upper pole (ureterocele excision and unilateral reimplantation) while two had a nonfunctioning upper moiety (upper pole partial nephrectomy and ureteric stump removal if necessary).

Briefly, two children had complete reconstruction, including upper pole heminephrectomy, ureterocele excision and bilateral ureteric reimplantation. Seven 


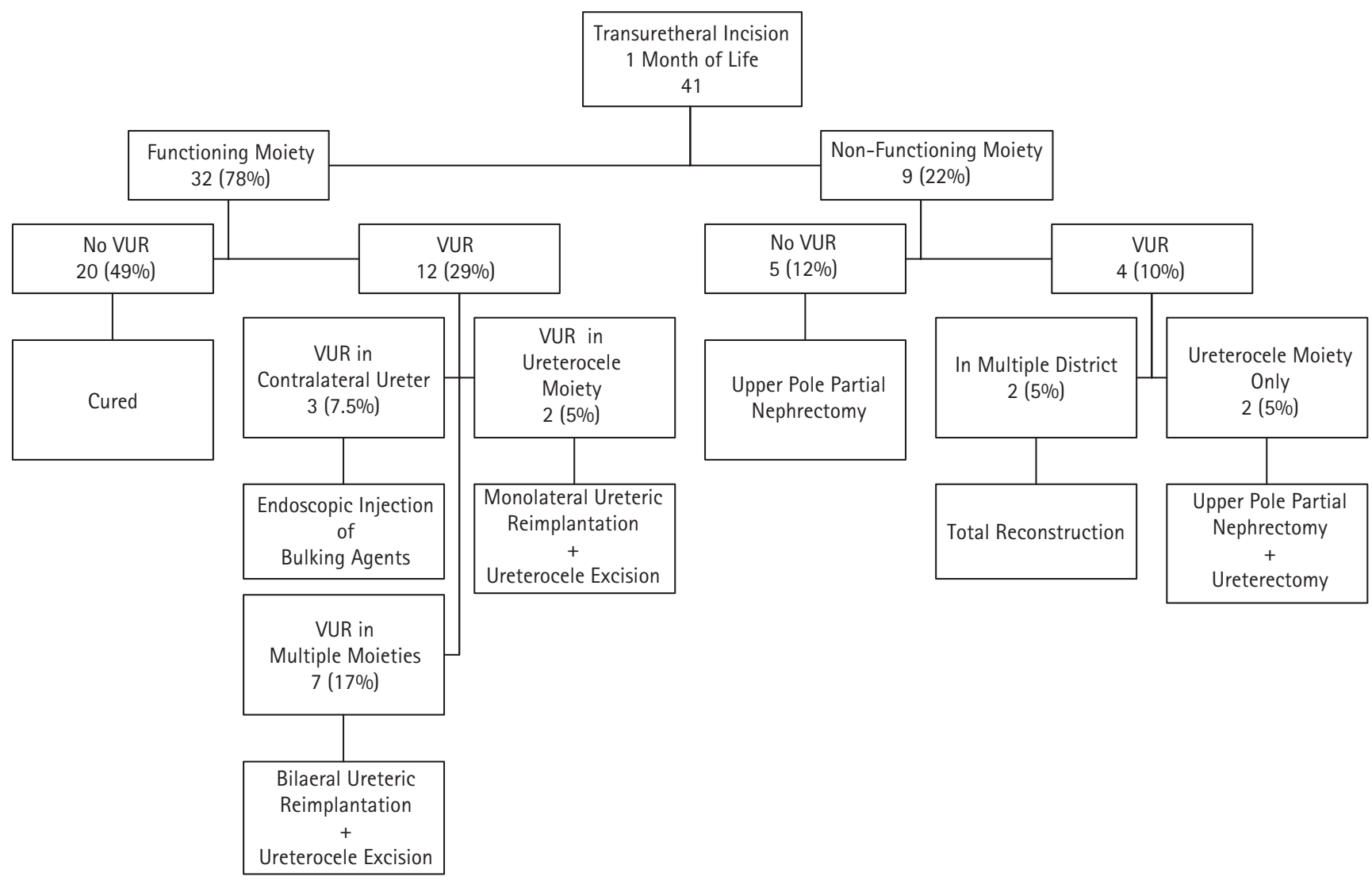

required an upper pole heminephroureterectomy, including two (5\%) who also had total ureterectomy for a refluxing stump. Nine patients needed surgery only at the bladder level, i.e. ureterocele excision and ureteric reimplantation. Reimplantation was cross-trigonal according to Choen in seven (three bilateral and four unilateral) and according to Politano-Leadbetter in two (both bilateral). A reimplantation according to Politano-Leadbetter was selected in these two children because they had a small trigone. The upper pole was preserved in 32 children (78\%); there was no difference in the secondsurgery rate between the intravesical and ectopic ureteroceles ( $P>0.05$; Table 1$)$. To the final follow-up none of the patients had vascular hypertension and none of the 28 aged $>4$ years had urinary incontinence.

\section{DISCUSSION}

The endoscopic transurethral approach is the minimally invasive method for treating ureterocele; its effectiveness in resolving impaired urinary flow is reportedly $76-100 \%$, the occurrence of de novo VUR in the punctured moiety 10-75\%, and its effectiveness as a single-stage treatment $15-90 \%$ [9-12,20-23]. Such variability may be a result both of technical aspects of the procedure or patient selection. For the former, currently it is well established that the incision should be made at the junction between the ureterocele and the bladder wall, to create a flap mechanism that avoids reflux after decompression. Creating a smal opening seems to be another crucial factor to prevent reflux, but it also increases the risk of unsatisfactory ureteric decompression. The Bugbee electrode, ureteric catheter stylet wire, Collin knife and laser, either puncturing or incising the ureterocele, have all been used $[2,9,11,18,22]$. We adopted the straightened loop of the resectoscope to create a $2-4 \mathrm{~mm}$ wide low opening in the ureterocele. This allowed successful decompression in 98\% of cases, whereas iatrogenic VUR appeared in 13 of 41 patients (32\%). Notably, the same incision was used in both ectopic or intravesical ureteroceles, and the de novo reflux rate in the punctured moiety was no different in the two groups. In contrast to an initial report [9], opening the ureterocele portion encroaching on or beyond the bladder neck is no longer advised [20]. Indeed, it only increases the risk of later reflux in the punctured moiety. However, no risk of B00 persists once the ureterocele collapses. This technical detail may partly explain the unfavourable outcome previously attributed to ectopic ureteroceles [9].

The appearance of VUR in the punctured moiety is considered the most adverse effect of ureterocele incision, as it potentially commits the patient to bladder surgery that could be avoided using a different initial approach from the upper tract [18]. However, de novo VUR in the ureterocele-bearing ureter was the indication for surgery in two of the present patients only (5\%). The remaining nine undergoing bladder surgery had associated VUR in a moiety with no ureterocele, persisting or appearing after puncture. We think that this feature is related to the effect of the ureterocele on the trigonal 
anatomy and the disappearance of a muscular backing of the trigone after ureterocele decompression. Therefore we suppose that the appearance of reflux in other moieties could not be avoided by an upper pole partial nephrectomy. Moreover, our impression is that such an effect is not strictly related to the size of the ureterocele but to its position with respect to the trigone, and is mostly unpredictable, as shown by the combination of resolving reflux or new VUR after incision.

We attempted the endoscopic treatment of VUR, i.e. a submucosal injection of bulking agents, only if there was VUR in the contralateral ureter after TUI. Chertin et al. [21] used the endoscopic correction of VUR systematically and only one of 16 patients failed to respond, requiring an open surgical reimplantation. Endoscopic treatment of VUR in the punctured ureterocele moiety was also proposed $[24,25]$. Although we are sceptical about this solution, as we think that the lack of muscular backing is unlikely to improve with bulking agents alone, it has also been used successfully $[21,23]$. The conservative treatment of refluxing ureters has also been reported more frequently. Using such an approach, Singh and Smith [26] noted that the tendency of patients to develop UTIs was unrelated to the presence of VUR; of 27 treated, 13 had VUR but never UTI, while three had UTI with no VUR. These authors therefore asked if reflux itself should be considered an indication for surgery.

The worst scenario after TUI is an isolated reflux in a nonfunctioning moiety; here, upper pole partial nephrectomy plus total ureterectomy could be required. Nevertheless, in our experience, this feature is rare, accounting for $5 \%$ of cases. Moreover, recent series suggest that a refluxing stump could be safely left in place, requiring additional surgery only in a few patients [27-29]. Further solutions could be the aforementioned endoscopic treatment or a heminephrectomy via a laparoscopic transperitoneal [30] or retroperitoneal [31] approach.

An argument often proposed against TUI in DSU is that the upper moiety is often dysplastic [13-15], its function negligible [32] and the potential for recovery poor [16]. Nevertheless evidence supporting this view is contradictory. While some studies reported the presence of dysplasia in more than twothirds of upper pole specimens [13-15], others found mainly inflammatory and obstructive changes [33]. Moreover, few studies have addressed specifically the problem in the neonatal setting, where a wider functional improvement could be possible. Smith et al. [32] reported a mean function after neonatal incision of 8.3\%, and we wonder whether such function could be considered negligible, considering that the pole usually accounts for a third of the kidney (theoretical function 17\%). We used no quantitative criterion to indicate partial nephrectomy, but the incidence of nonfunctioning poles in the present series, although slightly larger in the group with ectopic ureteroceles, was not statistically different in the two kinds of ureterocele. Nevertheless, the question is whether it is really necessary to remove a nonfunctioning upper pole whenever decompressed and not refluxing. According to the most recent trend, dysplastic renal tissue left in place is associated neither with a greater risk of malignancy nor with developing hypertension or infection [34]. Accordingly, five partial nephrectomies could have been avoided.

Recently some have proposed primary total reconstruction as the only effective singlestage treatment of DSU, at least in the presence of associated VUR $[6,7,17]$. Although we have no experience of this we agree that it seems to be the only approach able to address in one stage all the issues of a complex malformation like DSU. However, the feasibility of primary total reconstruction in experienced hands does not mean that it is not challenging and formidable when in widespread use. Furthermore, in the series of De Jong et al. [17], after total reconstruction including also systematic bladder-neck plasty, $35 \%$ of patients required secondary surgery and $10 \%$ chronic antibiotic chemoprophylaxis because of recurrent UTIs, and 27.5\% had dysfunctional voiding. An appealing solution could be a postponed primary reconstruction after a period of antibiotic prophylaxis. According to Husmann et al. [35] an initial observational approach would not increase the risk of B00 or UTIs. Nonetheless, the advantage of a single procedure should be weighed against the need for a double incision, particularly considering the reported evidence for a complete endoscopic, minimally invasive management of the disease [21].

In conclusion, our results confirm that DSU are cured in one stage by TUI in about half of patients, whereas further surgery is required in the other half $[12,20]$. The need for secondary surgery is particularly high when associated VUR is evident on VCUG before TUI $[12,36,37]$, and is caused exclusively by de novo VUR in the moiety bearing the ureterocele after TUI in a few cases (5\%). In a further 5\% de novo VUR appearing in a nonfunctioning moiety may require total ureterectomy. Although in our experience ectopic ureteroceles were more likely to have associated VUR or a nonfunctioning upper pole, in agreement with other recent series $[21,23]$, there was no significant difference between intravesical and ectopic cases in the occurrence of VUR in the punctured moiety, the rate of nonfunctioning upper poles or need for secondary surgery. Therefore we think such a distinction is clinically useless, especially considering the need for cystoscopy for a definitive assessment in 25\% of cases. In agreement with recent reports, the need for open secondary surgery could be drastically reduced by treating refluxing ureters endoscopically [21] or conservatively [26] and leaving in place nonfunctioning upper poles whenever drained by nonrefluxing ureters [34], and refluxing stumps after partial nephrectomy [27-29].

\section{CONFLICT OF INTEREST}

None declared.

\section{REFERENCES}

1 Peters CA. Urinary tract obstruction in children. J Urol 1995; 154: 1874-83

2 Douglas EC, Duckett JW. The modern approach to ureteroceles. J Urol 1995; 153: 166-71

3 Colin MJ, Skoog SJ, Tank ES. Current management of ureteroceles. Urology 1995; 45: 357-62

4 Monfort G, Morisson-Lacombe G, Coquet M. Endoscopic treatment of ureterocele revisited. J Urol 1985; 133: 1031-3

5 Di Benedetto V, Morrison-Lacombe G, Bagnara $\mathrm{V}$ et al. Transurethral puncture of ureterocele associated with single collecting system in neonates. J Pediatr Surg 1997; 32: 1325-7

6 Shekarriz B, Upadhyay J, Fleming P etal. Long-term outcome based on the initial surgical approach to ureterocele. J Urol 1999; 162: 1072-6

7 Decter RS, Sprunger JK, Holland RJ. Can 
a single individualized procedure predictably resolve all the problematic aspect of the pediatric ureterocele? J Urol 2001; 165: 2308-10

8 Coplen DE, Barthold JS. Controversies in the management of ectopic ureteroceles. Urology 2000; 56: 665-8

9 Blynt B, Passerini-Glazel G, Camuffo C et al. Endoscopic incision of ureteroceles: intravesical versus ectopic. J Urol 1993; 149: 556-8

10 Cooper CS, Passerini-Glazel G, Hutcheson JC et al. Long-term followup of endoscopic incision of ureteroceles: intravesical versus ectopic. J Urol 2000; 164: 1097-9

11 Jelloul J, Berger D, Frey P. Endoscopic management of ureterocele in children. Eur Urol 1997; 32: 321-4

12 Jyanthi VR, Koff SA. Long-term outcome of transurethral puncture of ectopic ureteroceles: initial success and late problem. J Urol 1999; 162: 1077-80

13 Rickwood AMK, Reiner I, Jones M et al. Current management of duplex system ureteroceles: experience with 41 patients. Br Urol 1992; 70: 196-200

14 Abel C, Lendon M, Gough DC. Histology of the upper pole in complete urinary duplication: does it affect surgical management? Br J Urol 1997; 80: 663-5

15 Bolduc S, Upadhyay J, Sherman C et al. Histology of upper pole is unaffected by prenatal diagnosis in duplex system ureteroceles. J Urol 2002; 168: 11236

16 Vates TS, Bukowski T, Triest J et al. Is there a best alternative to treating the obstructed upper pole? J Urol 1996; 156 : 744-6

17 De Jong TPVM, Dik P, Klijn AJ et al. Ectopic ureterocele. results of open surgical therapy in 40 patients. J Urol 2000; 164: 2040-4

18 Husmann D, Strand B, Ewalt D et al. Management of ectopic ureterocele associated with renal duplication: a comparison of partial nephrectomy and endoscopic decompression. J Urol 1999; 162: 1406-9

19 Glasberg KI, Braren V, Ducket JW et al. Suggested terminology for duplex system, ectopic ureters and ureteroceles. J Urol 1984; 132: 1153-4

20 Hagg MJ, Mourachov PV, Snyder HM et al. Modern endoscopic approach to ureterocele. J Urol 2000; 163: 940-3

21 Chertin B, De Clauwe D, Puri P. Is primary endoscopic puncture of ureterocele a long-term effective procedure? J Pediatr Surg 2003; 38: 116-9

22 Marr L, Skoog SJ. Laser incision of ureterocele in the pediatric patient. J Urol 2002; 167: 280-2

23 Chertin B, Fridmans A, Hadas-Halpren I et al. Endoscopic puncture of ureterocele as a minimally and effective long-term procedure in children. Eur Uro/ 2001; 39: 332-6

24 Diamond T, Boston VE. Reflux following endoscopic treatment of ureteroceles. A new approach using endoscopic subureteric Teflon injection. Br J Urol 1987; 60: 279-80

25 Viville C. Endoscopic treatment of ureterocele and antireflux injection with Teflon paste. Eur Urol 1990; 17: 321

26 Singh SJ, Smith G. Effectiveness of primary endoscopic incision of ureteroceles. Pediatr Surg Int 2001; 17 : 528-31

27 Androulakakis PA, Stephanidis A, Antoniou $A$ et al. Outcome of the distal ureteric stump after (hemi) nephrectomy and subtotal ureterectomy for reflux or obstruction. BJU Int 2001; 88: 586-9

28 De Caluwe D, Chertin B, Puri P. Fate of the retained ureteral stump after upper pole heminephrectomy in duplex kidneys. J Urol 2002; 168: 679-80

29 Barroso U, Calado AA, Zerati Filho $M$. The role of distal ureteral stump after nephrectomy. J Pediatr Surg 2002; 37 653-6

30 Janetschek G, Seibold J, Radmayr C et al. Laparoscopic heminephrectomy in pediatric patients. J Urol 1997; 158: 1928-30

31 El-Ghoneimi A, Valla JS, Steyaert H et al. Laparoscopic renal surgery via a retroperitoneal approach in children. J Urol 1998; 160: 1138-41

32 Smith C, Gosalbez R, Parrot TS et al. Transurethral puncture of ectopic ureteroceles in neonates and infants. J Urol 1994; 152: 2110-2

33 Monfort G, Guys JM, Coquet M et al. Surgical management of duplex ureteroceles. J Pediatr Surg 1992; 27: 634-8

34 Husmann DA. Renal dysplasia: the risk and consequences of leaving dysplastic tissue in situ. Urology 1998; 52: 5336

35 Husmann DA, Strand WR, Ewalt DH et al. Is endoscopic decompression of the neonatal extravesical upper pole ureterocele necessary for prevention of urinary tract infections or bladder neck obstruction? J Uro/ 2002; 167: 1440-2

36 Churchill BM, Sheldon CA, McLorie GA. The ectopic ureterocele: a proposed practical classification based on renal unit jeopardy. J Pediatr Surg 1992; 27: 497500

37 DeFoor W, Minevich E, Tackett L et al. Ectopic ureterocele: clinical application of classification based on renal unit jeopardy. J Urol 2003; 169: 1092-4

Correspondence: M. Castagnetti, MD, Via Ugo Betti, 46, 90100 Palermo, Italy. e-mail: marcocastagnetti@hotmail.com

Abbreviations: DSU, duplex system ureteroceles; TUI, transurethral incision; US, ultrasonography; VCUG, voiding cystourethrography. 